\title{
ResearchGate
}

See discussions, stats, and author profiles for this publication at:

https://www.researchgate.net/publication/229506516

\section{Self-Silencing to Sexism}

Article in Journal of Social Issues · September 2010

DOI: $10.1111 / \mathrm{j} .1540-4560.2010 .01658 . x$

CITATIONS

READS

20

115

4 authors, including:

\section{Janet Swim}

Pennsylvania State Unive...

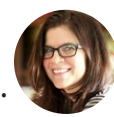

Melissa J Ferguson

Cornell University

80 PUBLICATIONS 4,590

45 PUBLICATIONS 2,456

CITATIONS

CITATIONS

SEE PROFILE

SEE PROFILE

Some of the authors of this publication are also working on these related projects:

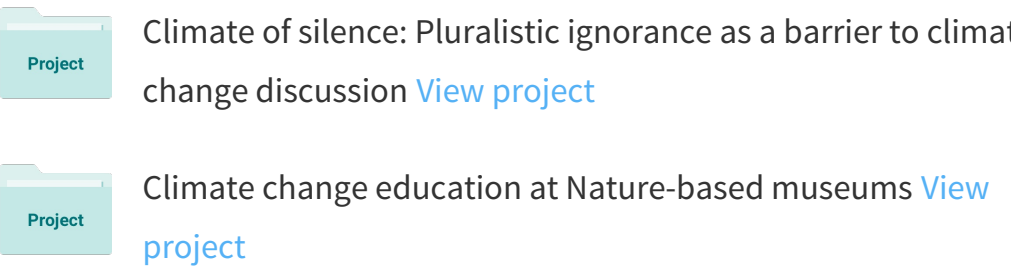




\title{
Self-Silencing to Sexism
}

\author{
Janet K. Swim*
}

The Pennsylvania State University

\section{Kristen M. Eyssell}

University of Baltimore

\section{Erin Quinlivan Murdoch}

University of Central Florida

\section{Melissa J. Ferguson}

\section{Cornell University}

Women's endorsement of beliefs that prioritize others' voices over their own (i.e., self-silencing beliefs) predicted behaviorally self-silenced to everyday, interpersonal forms of sexism. Self-silencing beliefs, which are consistent with prescriptive gender roles for women, indicate that one should avoid conflict in relationships, put others needs over one's own, accept a discrepancy between one's personal and public self, and judge one's behaviors by external standards. Results from a diary study indicate that the more U.S. college women endorsed self-silencing beliefs the less likely they wanted to respond to sexist incidents and, if they wanted to respond to incidents, the more they verbally restrained their responses to everyday sexism and other stressful incidents. The results suggest that, when addressing women's tendency to self-silence to incidents, one should address women's gender-role consistent beliefs about how they should behave in interpersonal interactions.

It is common for women to encounter prejudice and the display of discriminatory behavior embedded in their daily lives (Lim \& Cortina, 2005; Ramasubramanian \& Oliver, 2003; Settles, Cortina, Malley, \& Stewart, 2006; Swim, Hyers, Cohen, \& Ferguson, 2001). Everyday sexism includes comments

\footnotetext{
* Correspondence concerning this article should be addressed to Janet K. Swim, Department of Psychology, Pennsylvania State University, University Park, PA 16802 [e-mail: JSwim@psu.edu].

We would like to thank Anna Jordan for her assistance in data collection and data entry.
} 
and behaviors that form hostile work environments as well as nonprosecutable comments and behaviors that intertwine within the fabric of women's lives.

Although there are many reasons why women might confront everyday sexism, there are also many reasons not to confront (Hyers, 2007). Perhaps not surprisingly, then, it is common for women of all ages and ethnicities to remain silent to everyday sexism, causing a discrepancy between their private and publicly expressed opinions (Lott, Asquith, \& Doyon, 2001; Sechrist, Swim, \& Stangor, 2004; Swim \& Hyers, 1999). This discrepancy between wanting to say something and not saying something can be described as self-silencing. Silencing in discourse has been described as "a way of using language to limit, remove, or undermine the legitimacy of another [person's] use of language" (Thiesmeyer, 2003 , p. 2). Silencing can be overtly or, perhaps more commonly, covertly imposed upon others, particularly those in low power positions, and is a way of privileging some speakers over others. Silencing becomes self-silencing when individuals censure themselves. Although self-silencing may appear to be a choice, it is done within a social context that can impose negative consequences for speaking one's voice. For instance, undesirable consequences for confronting discrimination, such as being disliked, have been demonstrated (Kaiser \& Miller, 2001). Anticipating these reactions may be a reason why people do not confront discrimination.

For women, gender roles provide a social context encouraging self-silencing. These roles indicate that relationship maintenance is paramount to one's own needs and that women are to be deferential to others. Women's self-silencing becomes internally directed when they use an external standard to determine whether they should speak and when they believe that speaking one's voice threatens relationships they believe they are responsible for maintaining (Jack, 1991). The purpose of the present research is to test whether women's internalization of self-silencing supportive beliefs can help explain women's tendency to self-silence behaviorally to everyday forms of sexism. Addressing these belief systems could be important if one wants to encourage women to verbally confront sexism.

\section{Ask, Answer, Announce Model}

Our theoretical framework for understanding self-silencing behaviors is based upon a three-stage model of labeling discrimination deemed the ask, answer, and announce model (Sechrist \& Swim, 2008; Stangor et al., 2003). The first two stages determine whether individuals perceive an incident to be discriminatory. First, a person must be sufficiently aware of an incident and perceive that it might be considered sexist (i.e., ask if an incident is sexist). If a person does not ask if an incident is sexist, perhaps because the behavior is seen as normative, then she or he would not have a reason to confront the sexist nature of the incident. If a person questions whether an incident is sexist but decides it is not sexist (Swim, Scott, 
Sechrist, Campbell, \& Stangor, 2003; i.e., their answer to the question is that the incident is not sexist), then there is no reason to confront the sexist nature of the incident. We do not consider these two reasons for not confronting a sexist incident to be self-silencing. Self-silencing behavior occurs in the last stage of the model. In this stage, an incident is labeled as sexist and the person then decides whether to publicly indicate (i.e., announce) his or her opinion to others. Not publically responding can be because they either do not want to respond or they do not act on their desire to respond. We define self-silencing as wanting to say something but not saying it.

A number of individual differences and situational factors can potentially influence whether a person will announce her or his opinion. In the present research, we predict that women's endorsement of self-silencing beliefs, that is, a set of beliefs that direct people to prioritize others' voices in relationships over one's own, will be associated with self-silencing behaviors and in particular, self-silencing to sexism.

\section{Self-Silencing Beliefs}

According to self-silencing theory (Jack, 1991), some women have cognitive schemas for relationship maintenance that lead them to suppress thoughts and feelings that may jeopardize the harmony of their relationships. These schemas derive from gender-related beliefs about appropriate behavior for women in interpersonal interactions. They may also reflect women's actual or perceived lack of power in relationships. Women who repeatedly self-silence compromise their own values and beliefs for the sake of others, essentially allowing their desired outer self to mask their true inner self. A woman who believes that society deems it inappropriate for her to comment on a particular matter, or that making such comments would potentially offend others and threaten a relationship, will self-silence to behave appropriately for her gender.

We were interested in the predictive power of individual difference in endorsement of self-silencing beliefs for two reasons. First, we predicted that selfsilencing would have a particularly strong impact on women's decisions about whether to verbally respond to everyday sexism. Theoretically, endorsing selfsilencing beliefs should be related to silencing to a number of different types of behaviors. However, we anticipated that self-silencing beliefs, for women, may be particularly potent when considering whether to respond to everyday sexism. The pressure to comply with gender roles can be communicated through everyday sexism, thus, highlighting the relationship beliefs that prescribe silence in women. Further, everyday sexism can be a means of communicating social power over women and may reinforce the disempowering beliefs associated with self-silencing beliefs.

Second, self-silencing theory specifies four different reasons why women might choose to self-silence, and these different reasons might help to clarify 
reasons why women self-silence to everyday sexism. The four reasons to selfsilence are reflected in four subscales of the self-silencing scale: externalized self-perception, divided self, conflict avoidant self-silencing, and care as selfsacrifice (Jack, 1991; Jack \& Dill, 1992).

Two reasons for self-silencing reflect a tendency to allow the outer self to be dictated by external standards and for women this includes prescriptive gender roles that indicate that women should consider their thoughts and feelings as being less valid or important than others' thoughts and feelings. Externalized selfperception refers to a tendency to self-silence because women judge themselves by external standards more than their own internal standards. The divided self refers to a tendency to accept a discrepancy between one's outward self and one's true inner feelings. Theoretically, Jack described the divided self as being "the experience of presenting an outer, compliant self to live up to feminine role imperatives while the inner self grows angry and hostile" (Jack \& Dill, 1992, p. 98).

Several studies have demonstrated the effect of self-presentation concerns on confronting discrimination (Sechrist et al., 2004; Shelton \& Stewart Steward, 2004; Stangor et al., 2003; Swim \& Hyers, 1999). This research suggests that the divided self and externalized self-perceptions components of Jack's self-silencing scale would both relate to self-silencing because they are related to self-presentation concerns.

Two other reasons for self-silencing reflect relationship concerns. Conflict avoidant self-silencing refers to the tendency to restrain one's thoughts or feelings to avoid conflict in a relationship. Care as self-sacrifice refers to women's tendency to put others' needs and opinions before their own. Avoiding conflict and caring for others are consistent with both prescriptive gender roles dictating that women should care for others and relationships, as well as with gender stereotypes about women being more communal or nurturing than men.

We anticipated that relationship beliefs that support self-silencing would also be related to behaviorally self-silencing to sexism. Women may be reluctant to confront discrimination because it can indicate that they are accusing someone they know of being prejudiced (Crosby, 1984). Thus, women who are concerned with others' needs over their own would not want to make others feel bad, even when the other has done something hurtful. In other words, even if silencing comes at the expense of a woman's own feelings, she may think that confronting discrimination would be selfish. We are aware of only one study that has examined the effects of relationship concerns on confronting (Hyers, 2007). This diary study revealed that one reason women reported for not confronting discrimination was that they want to avoid getting into a conflict (Hyers, 2007). Given the logic proposed by others and the findings from Hyers (2007), we anticipated that relationship concerns reflected in the conflict avoidant and care as relationship components of Jack's self-silencing scale would also predict self-silencing behaviors. 


\section{Present Research}

Women completed Jack's self-silencing scale, identifying the extent to which they endorsed four reasons for self-silencing, completed structured daily diaries for 1 week where they reported their experiences with and responses to everyday sexism as well as other forms of everyday hassles. Participants were given a list of behaviors they might experience during the week and, if they experienced any of the incidents, they rated the extent to which they perceived the incidents as sexist and the extent to which they wanted to and did overtly respond to the incidents.

We predicted that the more women endorsed self-silencing beliefs, the less likely they would be to fully respond to incidents, and this would be particularly true for incidents they identified as sexist for reasons noted above. Or put differently, we anticipated that the more incidents were perceived as sexist, the more likely women would respond to the incidents (perhaps because they would be more angry or they thought they could more easily defend their opinion), but this greater desire would be suppressed the more women endorsed self-silencing beliefs. Thus, we predicted main effect for self-silencing beliefs and perceptions of sexism that would be qualified by an interaction between self-silencing beliefs and perceptions of incidents as sexist such that the negative relationship between perceptions of incidents as sexist and silencing to sexist incidents would be weaker for those who endorsed self-silencing beliefs than for those who did not endorse these beliefs.

We decompose this predicted relationship into two different parts of the decision to speak one's voice: wanting to speak one's voice and acting on that desire. Self-silencing beliefs could influence women's desire to respond and not just their tendency to act on the desire, although the latter better fits our definition of selfsilencing behaviors. Those who internalize self-silencing beliefs may suppress the motivation to respond and not just suppress actions that follow from the motivation.

We also explored whether each of the four different motivations for selfsilencing predicted self-silencing behaviors. We anticipated all four beliefs would be related to self-silencing behaviors as predicted above. However, it is possible that some beliefs may be more important than others, and this may be particularly true for responding to everyday sexist behaviors. For instance, it is possible that women may be angry enough at those who say something they perceive to be sexist that they do not care more for them than they care for themselves, decreasing the impact of relationship reasons for self-silencing.

\section{Method}

\section{Participants}

One-hundred and thirteen women participated in the present study either as volunteers or for course credit. Ninety-two percent of the sample was White. 
The student volunteers $(N=36)$ were recruited from a women's group on a small campus and the other participants were recruited from a general psychology course $(N=77)$ on the same campus. Data from two participants from the psychology course were excluded because the total number of incidents they reported exceeded three standard deviations above the mean number of incidents.

\section{Procedure}

Participants were told that the purpose of the study was to explore the circumstances and extent to which people desire to speak their opinions but choose not to say what they want to say. They first completed individual difference measures assessing their endorsement of self-silencing beliefs (Jack \& Dill, 1992), their endorsement of sex-role egalitarianism (King \& King, 1990), and the selfmonitoring scale (Snyder, 1974). The latter two beliefs were included to test for alternative predictors of self-silencing behavior. Their relations to self-silencing behaviors do not alter the conclusions presented below so we do not present this information.

Next, the diary measures were explained. They completed a diary at the end of each day for 7 days. Following completion of individual difference measures, participants were instructed on how to complete the diary forms. They were told to document any experience they had that was included in the diary sheet. They were also reminded that it was possible to have multiple incidents or none at all.

\section{Measures}

Self-silencing beliefs. Participants first completed Jack and Dill's (1992) the self-silencing scale (Cronbach's $\alpha=.88$ ). Responses were completed on 5 -point scales ranging from strongly disagree $(-2)$ to strongly agree $(+2)$. The scale consists of four subscales: externalized self-perception (e.g., "I tend to judge myself by how I think other people see me," and "When I make decisions, other people's thoughts and opinions influence me more than my own thoughts and opinions"; Cronbach's $\alpha=.70$, six items), divided self (e.g., "Often I look happy enough on the outside, but inwardly I feel angry and rebellious" and "I feel I have to act in a certain way to please my partner"; Cronbach's $\alpha=.77$, seven items), conflict avoidant self-silencing (e.g., "Instead of risking confrontations in close relationship, I would rather not rock the boat" and "I rarely express my anger at those close to me"; Cronbach's $\alpha=.86$, nine items), and care as self-sacrifice (e.g., "Caring means choosing to do what the other person wants, even when I want to do something different" and "Doing things just for myself is selfish"; Cronbach's $\alpha=72$, eight items). 
Diary measures. The diary form listed nine types of incidents participants might experience and a 10th category for incidents that did not fit within the nine categories. The first three incidents measured sexist experiences, the second three measured racist experiences, and the last four measured experiences likely unrelated to prejudice. Because $92 \%$ our participants were White and reported relatively few racist incidents, we excluded reports about the three types of racist incidents listed on the diary form.

The incident types listed in the diary came from coding of open-ended responses in previous diary studies where college students identified everyday sexist incidents that they experienced (Swim et al., 2001). They were not directly labeled as being sexist or not. The sexist incident consisted of (1) stereotypes or assumptions based upon gender (e.g., assumed to have or not have certain traits, abilities, or preferences, such as being bad at math or liking to shop because of his or her gender), (2) unwanted sexual attention (e.g., staring, ogling, touching), and (3) comments or behaviors that indicate gender-based dislike, disrespect, or insensitivity (e.g., use of derogatory terms such as "bitch"). There was no specification that the sexist incidents had to be directed at women nor at the target personally. However, our past research (Swim et al., 2001) and pilot data suggest that these are the likely targets of the behaviors women would report and incidents directed at other women or women in general could be experienced as being directed at the self.

The nondiscriminatory incidents were derived from research on everyday stressors that college students typically experience (Osman, Barrios, Langnecker, \& Osman, 1994). These incidents consisted of (1) romantic relationship problems (e.g., romantic partner pays too much attention to someone else), (2) roommate problems/conflicts/concerns (e.g., disagreement about noise), (3) problems with school (e.g., difficulty with group work-some members are unreliable), and (4) "any other incident that bothered you during the day that does not fit into the above categories." Participants could perceive these incidents as sexist, but their content and previous research suggests they would be unlikely to be perceived as sexist.

Rating of incidents. If participants experienced any of the different types of incidents during the day they were asked to providing ratings of the incident. If they did not experience a particular type of incident, they made no rating for that incident type. If they did not have any experiences with any of the incidents on a particular day, they noted that at the top of the form. Endorsing self-silencing beliefs was unrelated to the number of sexist incidents they reported suggesting that self-silencing beliefs did not influence whether they noticed sexist incidents (the ask part of ask, answer, announce model). Participants used 5-point scales to indicate how sexist the incident was $(-2=$ definitely not sexist, $-1=$ probably not sexist, 0: Uncertain, 1 = probably sexist, 2 = definitely sexist). 
Table 1. Correlation among Subscales of the Self-Silencing Scale

\begin{tabular}{lcccc}
\hline & Externalize the Self & Divided Self & Conflict Avoidant & Care as Self-Sacrifice \\
\hline Mean $(S D)$ & $2.48(.51)$ & $2.81(.72)$ & $2.33(.74)$ & $2.77(.59)$ \\
Externalize the self & 1.00 & & & \\
Divided self & $.43^{* * *}$ & 1.00 & & \\
Conflict avoidant & $.52^{* * *}$ & $.57^{* * *}$ & 1.00 & 1.00 \\
Care as self-sacrifice & $.40^{* * *}$ & .13 & $.42^{* * *}$ & \\
\hline$d f=110 ; * * * p<.001$. & & &
\end{tabular}

Participants then indicated how they responded to the incident. They indicated whether they (1) did not want to respond to the incident and did not respond to the incident, (2) wanted to say something but did not say anything, (3) wanted to say something but said only part of what they wanted to say, and (4) wanted to say something and said all they wanted to say. Not wanting to respond was indicated by the first option. Degree of self-silencing was indicated by the last three ratings.

\section{Results}

\section{Analyses}

We use multilevel modeling because each woman reported multiple and varying numbers of incidents (Kenny, Kashy, \& Bolger, 1998). We used grand mean centering for our level 2 predictor variables (i.e., endorsement of self-silencing beliefs and subscales of the self-silencing scale) and group mean centering for the level 1 predictor variable (perceptions of the extent to which incidents were sexist) (Enders \& Tofighi, 2007). We conducted analyses separately for each of the subscales because they were highly correlated with each other (see Table 1). Analyses predicting the extent to which women expressed themselves include cross-level effects. In these analyses, this refers to testing whether the relationship between characteristics of the incident (level 1 sexism ratings) and the outcome variable (e.g., level 1 ratings of responding to incidents) differed by characteristics of the respondents (level 2 endorsement of self-silencing beliefs). In other words, it tests the interaction between characteristics of the incident and characteristics of the person on the extent to which they reported expressing themselves.

\section{Experiences with Sexist Incidents}

Women reported, on average, 11.94 of incidents per person per week of the study. Over the course of 1 week, on average, each woman reported 5.55 incidents 


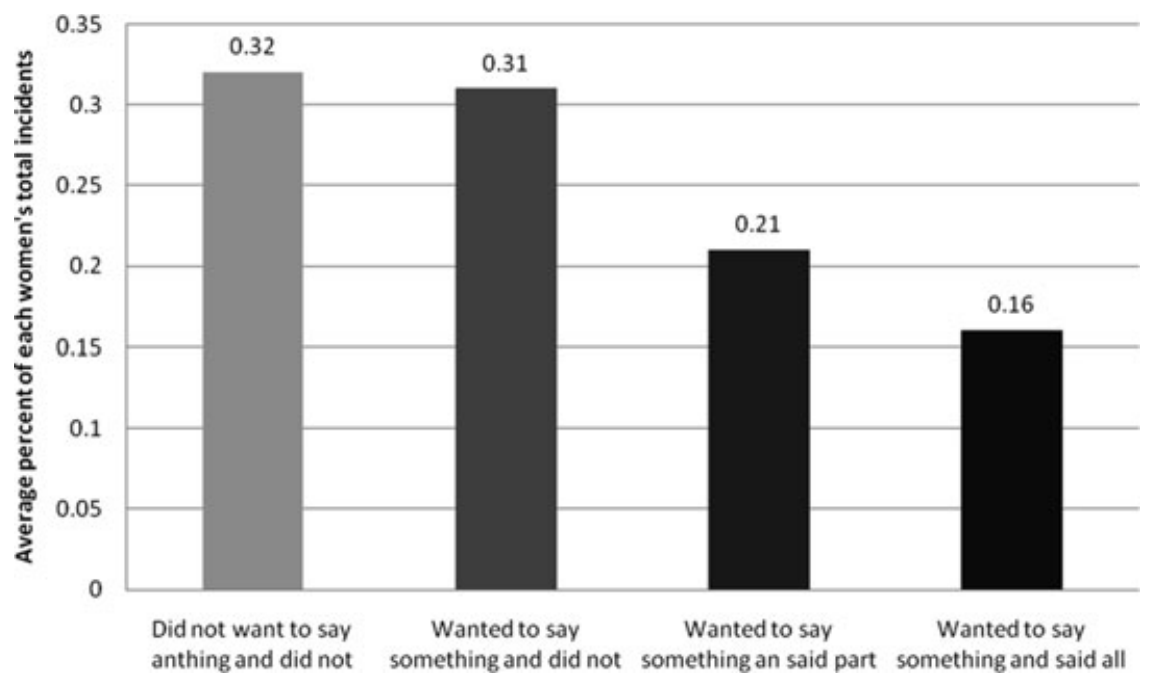

Fig. 1. Likelihood that women gave different types of responses to incidents.

they rated as probably or definitely sexist, 3.69 incidents that they rated as probably or definitely not sexist, and 2.48 incidents per week that they were uncertain as to whether they were sexist. Multilevel modeling indicating that the more women endorsed self-silencing beliefs, the more likely they rated incidents as sexist, slope $=.27, t(109)=2.40, p=.02$. Follow-up analyses indicates that this was a function of the two self-silencing subscales that were related to self-presentation concerns (externalizing the self: slope $=.22, t(109)=2.16, p=.03$ and divided self: slope $=.22, t(109)=2.51, p=.01$, but not the two subscales that assessed relationship concerns: conflict avoidant: slope $=.16, t(109)=1.60, p=.11$ and care-as-self-sacrifice, slope $=-.01, t(109)=-.06, p=.95$.

\section{Announcing One's Opinion}

As illustrated in Figure 1, women did not want to respond to about one third of the incidents they reported. Complete self-silencing would be indicated by wanting to say something and not saying anything at all. This occurred for an additional one third of the incidents. In only about $15 \%$ of the incidents women wanted to say something and said all that they wanted to say. Next we examined whether endorsing self-silencing beliefs, perceiving incidents as sexist, and the interaction between these two variables predicted wanting to respond and, when women wanted to respond, the extent to which women behaviorally silenced themselves. 


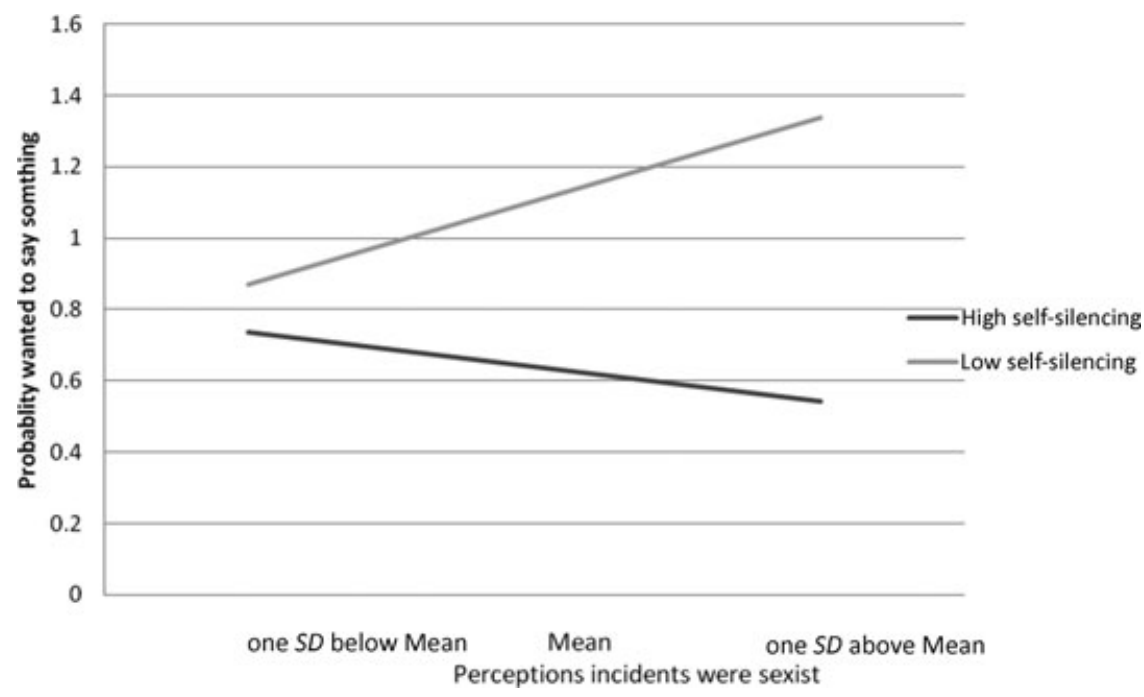

Fig. 2. Predicting wanting to say something by perceptions incidents are sexist for those who do and do not endorse self-silencing beliefs.

Wanting to respond. We created a dichotomous variable out of the scale assessing the extent to which women indicated that they expressed themselves after each incident. The measure indicate that women either (1) did not want to respond and did not or (2) wanted to respond and may or may not have actually responded. Thus, in our multilevel modeling, we tested the probability that women did not want to respond to the incidents they reported.

The interaction between women's responses to the total self-silencing scale and perceptions that the incident was sexist was significant, slope $=-.21$, $t(1245)=1.97, p=.05$. As illustrated in Figure 2, women who were less likely to endorse self-silencing beliefs (i.e., low on the self-silencing scale) were more likely to want to respond to incidents, the more they perceived incidents to be sexist, slope $=.16, t(577)=1.95, p=.05$. In contrast, women who were less likely to endorse self-silencing beliefs (i.e., high on the self-silencing scale) were not more likely to want to respond, the more they perceived incidents to be sexist, slope $=-.07, t(623)=.96, p=.33$. Or examined differently, where as endorsing self-silencing beliefs was unrelated to responding to incidents perceived to nonsexist, slope $=.04, t(84)=.63, p=.53$, the more women endorsed self-silencing beliefs the less likely they were to want to respond to sexist incidents, slope $=$ $-.12, t(96)=2.06, p=.04$.

Follow-up analyses of the subscales indicated that this interaction was significant for externalizing the self, slope $=-.17, t(1245)=2.38, p=.02$, and 
care as self-sacrifice, slope $=-.21, t(1245)=2.44, p=.02$, and marginally significant for conflict avoidance, slope $=-.11, t(1245)=1.63, p=.10$. As with the total scale, perceiving incidents as sexist was related to being more likely to want respond for those who did not endorse externalizing beliefs, slope $=.14$, $t(551)=1.93, p=.05$, conflict avoidant beliefs, slope $=.17, t(559)=2.23, p=$ .02 , and care as self-sacrifice, slope $=.12, t(514)=1.54, p=.25$, although the latter was not statistically significant. Perceiving incidents as sexist was unrelated to being more likely to respond for those who endorsed externalizing beliefs, slope $=-.06, t(694)=.95, p=.34$, conflict avoidant beliefs, slope $=-.09$., $t(676)=2.23, p=.22$, and care as self-sacrifice, slope $=-.08, t(627)=1.37$, $p=.18$.

The one exception to this pattern was for the subscale assessing the extent to which women reported having a divided self (i.e., having a mismatch between their external and internal self). The interaction was not significant, slope $=.06$, $t(1245)=-.78, p=.43$, but there was a marginally significant main effect that indicated that the more women endorsed this self-silencing belief, the less they wanted to respond, slope $=-.27, t(109)=1.66, p=.10$. The lack of a significant interaction indicated that the relation between endorsing this belief and wanting to respond was present for incidents women perceived as more sexist as well as incident women perceived as not sexist.

Reports of self-silencing behavior. Next we analyzed the subset of incidents where women indicated that they wanted to say something in response to the incident. We recoded this variable so that higher numbers indicated more selfsilencing. The more participants perceived incident to be sexist the less likely they were to silence themselves ( $\operatorname{lope}=-.05, t(864)=-2.34, p=.02$ ). Additionally, the more women endorsed self-silencing beliefs, the more likely they reported behaviorally self-silencing. This was true for the total self-silencing scale (slope = $.27, t(104)=3.06, p=.003)$, the externalizing self subscale (slope $=.18, t(104)=$ 2.82, $p=.01$ ), the conflict avoidant self scale (slope $=.17, t(104)=2.75$, $p=.01)$, and the divided self scale (slope $=.16, t(104)=2.52, p=.01)$. The lack of significant interaction effects for these scales indicated that the tendency for self-silencing beliefs to be associated with behaviorally self-silencing was present for incidents participants perceived to be sexist and incidents they perceived to not be sexist.

The only significant interaction was between the caring as self-sacrificing subscale and perceiving incidents as sexist (care as self-sacrifice: slope $=-.07$, $t(863)=2.19, p=.03$ ). Contrary to predictions, perceiving incidents as sexist was related to being less likely to silence oneself for women who one endorsed these self-silencing beliefs (slope $=-.06, t(410)=2.17, p=.03$ ) and unrelated for women who did endorse these beliefs (slope $=-.02, t(370)=.59, p=.58$ ). 


\section{Discussion}

Consistent with past research that points to a reluctance to confront sexism, women did not fully respond to a substantial number of sexist incidents that they encountered in their everyday lives even though they defined them as sexist. This tendency to hold back one's response was more likely to be true for women who endorsed self-silencing beliefs.

The data indicate that behaviorally self-silencing was not unique to sexist incidents. If women wanted to respond to incidents, the more they endorsed self-silencing beliefs, the more likely they were to self-silence to both sexist and nonsexist incidents. Yet the association between self-silencing beliefs and wanting to respond did differ for sexist and nonsexist incidents. The tendency to endorse self-silencing beliefs decreased women's desire to respond to sexist but not to nonsexist incident.

Women who endorsed self-silencing beliefs were more likely to perceive incidents as sexist. This provides a potential explanation for the association between self-silencing beliefs and expressing one's opinion. Women who endorse self-silencing beliefs may perceive the sexist incidents to be more threatening as evidenced by being more likely to rate them sexist. This greater threat may have decreased their desire to respond.

The findings presented here have practical implications. These results support findings from lab studies that indicate that lack of confronting or publically labeling incidents as sexist is not necessarily indicative of not defining incidents as sexist (Sechrist et al., 2004; Stangor et al., 2002; Swim \& Hyers, 1999). The present study indicates that this is especially true for those who endorse self-silencing beliefs. This is interesting because these beliefs are consistent with traditional gender role prescriptions about how women should behave in interpersonal interaction: One might have expected that women who follow traditional gender roles to be more likely to self-silence because they would be less likely to perceive or label incidents as sexist. Yet our data do not support this expectation because effects of self-silencing beliefs emerged among the incidents that were labeled as sexist. The findings suggest that if one wanted to encourage women to verbally respond to sexism in their personal lives, then one should attend to relationship beliefs that influence women's desire to speak up in interpersonal interactions more so than, for instance, whether they define incidents as sexist.

\section{Different Types of Self-Silencing Beliefs}

For the most part, the above results were consistent across the different types of self-silencing beliefs. However, there were some exceptions. First, the tendency for self-silencing beliefs to be associated with less desire to respond to sexist incidents but not nonsexist incidents was not found for the subscale assessing the extent to which women's public selves did not match their private selves (i.e., 
divided self). Second, opposite to predictions, increased sexism was related to less self-silencing for those who believed silencing was a way to care for others but unrelated for those who did not share this belief. Perhaps, encountering sexist incidents crosses a threshold such that women no longer feel the need to sacrifice their own personal opinions for the sake of protecting others; the insult of the sexist behavior may override their care for the other person. Future research should look more closely into possible reasons why these two subscales resulted in different results than the other subscales.

\section{Limitations and Future Research}

The present study provided participants with a list of behaviors to consider when reporting their daily experiences with different forms of everyday stressors that likely increased women's tendency to notice incidents (Swim et al., 2001). If we had not provided the list, differences in responding to sexist incidents might be greater because there could possibly be differences in the number of incidents they report with those who self-silencing reporting fewer incidents and therefore furthering the gap between those who endorse and do not endorse self-silencing beliefs. Yet it should also be noted that other types of beliefs, such as feministrelated beliefs, are not related to number of incidents women reported in daily diaries utilizing open-ended formats or check lists (Swim et al., 2001). Thus, it is also possible that self-silencing beliefs would not be related to noticing sexist incidents even if we did not provide the list.

Future research might examine the moderating role of characteristics of the experiences. One could examine self-silencing behaviors in different types of relationships including relationships that vary in closeness and power differentials of the relationship (Barreto, Ellemers, \& Fiske, this issue). Additionally, the target of the incident could be coded. Caring for others might predict speaking up on behalf of specific others more so than for one's self. Future research might examine the generalizability of the present findings to different age and ethnic groups. Different ethnic groups respond differently to racism (Lee, Swim, \& Soto 2010) and there are ethnic group differences in endorsement of self-silencing beliefs (e.g., Gratch, Bassett, \& Attra, 1995). Thus, endorsement of self-silencing beliefs may account for differences in ethnic group responses to incidents. Future research could examine whether endorsement of self-silencing beliefs is related to other forms of silencing as well, such as hiding a concealable stigma (Chaudoir \& Quinn, this issue).

Finally, future research should specifically examine why women who endorse self-silencing beliefs are particularly unlikely to want to respond to sexist incidents. Perhaps they are psychologically invested in maintaining gender roles, in the same manner that low- and high-status people show a preference for the status quo (Jost, Pelham, Sheldon, \& Sullivan, 2003). Indicating that one does not want to respond may allow women to not feel responsible for challenging sexism and may relieve them of the guilt they might feel for not responding. 


\section{Conclusion}

Self-silencing beliefs inhibit women from fully expressing themselves. Consistent with prescriptive gender roles, self-silencing beliefs prescribe avoidance of conflict in relationships, putting others needs over one's own, accepting a discrepancy between one's personal and public self, and judging one's behaviors by external standards. Endorsing these beliefs is associated with being less likely to want to respond to sexism more so than wanting to respond to other interpersonal stressors that were not perceived as sexist. Further, once they want to respond, endorsing these beliefs is associated with restricting one's response to everyday sexism and other everyday forms of interpersonal difficulties.

\section{References}

Barreto, M., Ellemers, N., \& Fiske, S. T. (2010). "What did you say, and who do you think you are?" How power differences affect emotional reactions to prejudice. Journal of Social Issues, 66(3), $477-492$.

Chaudoir, S. R., \& Quinn, D. M. (2010). Revealing concealable stigmatized identities: The impact of disclosure motivations and positive first disclosure experiences on fear of disclosure and well-being. Journal of Social Issues, 66(3), 570-584.

Crosby, F. (1984). The denial of personal discrimination. American Behavioral Scientist, 27, 371-386.

Enders, C. K., \& Tofighi, D. (2007). Centering predictor variables in cross-sectional multilevel models: A new look at an old issue. Psychological Methods, 12, 121-138.

Gratch, L. V., Bassett, M. E., \& Attra, S. L. (1995). The relationship of gender and ethnicity to self-silencing and depression among college students. Psychology of Women Quarterly, 19(4), $509-515$.

Hyers, L. L. (2007). Resisting prejudice every day: Exploring women's assertive responses to anti-black racism, anti-semitism, heterosexism, and sexism. Sex Roles, 56(1-2), $1-12$.

Jack, D. C. (1991). Silencing the self: Women and depression. Cambridge, MA: Harvard University Press.

Jack, D. C., \& Dill, D. (1992). The silencing the self scale: Schemas of intimacy associated with depression in women. Psychology of Women Quarterly, 16, 97-106.

Jost, J. T., Pelham, B. W., Sheldon, O., \& Sullivan, B. N. (2003). Social inequality and the reduction of ideological dissonance on behalf of the system: Evidence of enhanced system justification among the disadvantaged. European Journal of Social Psychology, 33(1), 13-36.

Kaiser, C. R., \& Miller, C. T. (2001). Stop complaining! The social costs of making attributions to discrimination. Personality and Social Psychology Bulletin, 27(2), 254-263.

Kenny, D. A., Kashy, D. A., \& Bolger, N. (1998). Data analysis in social psychology. In D. T. Gilbert, S. T. Fiske, \& G. Lindzey (Eds.), The handbook of social psychology (4th ed., Vol. 1, pp. 233-265). New York: McGraw-Hill.

King, L. A., \& King, D. W. (1990). Abbreviated measures of sex role egalitarian attitudes. Sex Roles, 23(11-12), 659-673.

Lee, E. A., Swim, J. K., \& Soto, J. A. (2010). “Don't get me wrong. ..”: Cultural differences in actual and expected confronting behavior in response to discrimination. Manuscript submitted for publication.

Lim, S., \& Cortina, L. M. (2005). Interpersonal mistreatment in the workplace: The interface and impact of general incivility and sexual harassment. Journal of Applied Psychology, 90(3), $483-496$.

Lott, B., Asquith, K., \& Doyon, T. (2001). Relation of ethnicity and age to women's responses to personal experiences of sexist discrimination in the united states. Journal of Social Psychology, 141(3), 309-322. 
Osman, A., Barrios, F. X., Langnecker, J., \& Osman, J. (1994). Validation of the Inventory of College Students' Recent Life Experiences in an American college sample. Journal of Clinical Psychology, 50, 856-863.

Ramasubramanian, S., \& Oliver, M. B. (2003). Portrayals of sexual violence in popular Hindi films, 1997-99. Sex Roles, 48, 327-336.

Sechrist, G. B., \& Swim, J. K. (2008). Psychological consequences of failing to attribute negative outcomes to discrimination. Sex Roles, 59(1-2), 21-38.

Sechrist, G. B., Swim, J. K., \& Stangor, C. (2004). When Do the stigmatized make attributions to discrimination occurring to the self and others? The roles of self-presentation and need for control. Journal of Personality and Social Psychology, 87(1), 111-122.

Settles, I. H., Cortina, L. M., Malley, J., \& Stewart, A. J. (2006). The climate for women in academic science: The good, the bad, and the changeable. Psychology of Women Quarterly, 30(1), 47-58.

Shelton, J. N., \& Stewart, R. E. (2004). Confronting perpetrators of prejudice: The inhibitory effects of social costs. Psychology of Women Quarterly, 28(3), 215-223.

Snyder, M. (1974). Self-monitoring of expressive behavior. Journal of Personality and Social Psychology, 30, 526-537.

Stangor, C., Swim, J. K., Sechrist, G. B., DeCoster, J., VanAllen, K. L., \& Ottenbreit, A. (2003). Ask, answer and announce: Three stages in perceiving and responding to discrimination. In W. Stroebe \& M. Hewstone (Eds.), European review of social psychology (Vol. 14, pp. 277-311). Hove, UK: Psychology Press/Taylor \& Francis.

Swim, J. K., \& Hyers, L. L. (1999). Excuse me-what did you just say? Women's public and private responses to sexist remarks. Journal of Experimental Social Psychology, 35, 68-88.

Swim, J. K., Hyers, L. L., Cohen, L. L., \& Ferguson, M. J. (2001). Everyday sexism: Evidence for its incidence, nature, and psychological impact from three daily diary studies. Journal of Social Issues, 57, 31-53.

Swim, J. K., Scott, E., Sechrist, G. B., Campbell, B., \& Stangor, C. (2003). The role of intent and harm in judgments of prejudice. Journal of Personality and Social Psychology, 84, 944-959.

Thiesmeyer, L. (2003). Discourse and silencing: Representation and the language of displacement. Amsterdam and Philadelphia: John Benjamins Publishing Co.

JANET K. SWIM, PhD, is a Professor of Psychology at The Pennsylvania State University. Her research addresses perceptions and responses to current social and environmental issues. This includes examining manifestations, consequences of, and affective and behavioral responses to contemporary forms of sexism, racism, and heterosexism. She is particularly interested in everyday manifestations of discrimination as these encounters weave into the fabric of our lives. Her current work also examines affective and behavioral responses to climate change and more generally environmental sustainability.

KRISTEN M. EYSSELL, PhD, is on the faculty at the University of Baltimore. Her research interests focus on relationship processes, the self, and on the impact of existential motives on a variety of self-relevant phenomena.

ERIN QUINLIVAN MURDOCH, PhD, is a Lecturer of Psychology at the University of Central Florida. Her research interests include the social construction of the self, self-presentation, body image, and prejudice.

MELISSA J. FERGUSON, PhD, is an Associate Professor in the Psychology Department at Cornell University. She studies attitudes, motivation, decisionmaking and ideology from an implicit cognition perspective. 
Copyright of Journal of Social Issues is the property of Wiley-Blackwell and its content may not be copied or emailed to multiple sites or posted to a listserv without the copyright holder's express written permission. However, users may print, download, or email articles for individual use. 